\title{
MEDIZINISCHES SEMINAR
}

HERAUSGEGEBEN VOM

WISSENSCHAFTLICHEN AUSSCHUSSE DES WIENER MEDIZINISCHEN DOKTORENKOLLEGIUMS

BAND IV

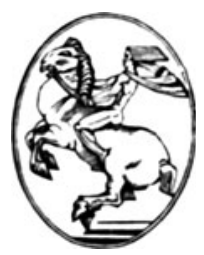

SPRINGER-VERLAG BERLIN HEIDELBERG GMBH 


\section{ALIE RECHTE, INSBESONDERE DAS DER UBERSETZUNG}

IN FREMDE SPRACHEN, VORBEHALTEN

Softcover reprint of the hardcover 1st edition 1932

ISBN 978-3-7091-5284-3

ISBN 978-3-7091-5432-8 (eBook)

DOI $10.1007 / 978-3-7091-5432-8$ 


\section{Vorwort}

Die Seminarveranstaltungen des Wiener medizinischen Doktorenkollegiums entwickeln sich in aufsteigender Linie. Die Vortragsabende erfreuen sich regen Besuchs. Den Vorträgen und Diskussionen wird großes Interesse entgegengebracht.

Es erscheint mithin zweckmäßig, in vorliegendem 4. Bande die Sammlung der Referate fortzusetzen, welche die Vortragenden in kollegialer Hilfsbereitschaft uns zur Verfügung stellen. Dem Buche ist ein Sachregister angegliedert, welches sämtliche bisher erschienenen 4 Bände berücksichtigt.

Möge auch dieser Band des Seminarbuchs sich den Ärzten als guter Berater, als verläßliches Nachschlagewerk bewähren.

Wien, im Dezember I93I

I, Franz Josefs-Kai 65

Der wissenschaftliche Ausschuß

des Wiener medizinischen Doktorenkollegiums 